\title{
SPEECH ERROR IN “GET REAL GIVING THANKS WITH SAM KIM EP \#22 BY DIVE STUDIOS" VIDEO PODCAST
}

\author{
Ruth Intan Angraeni Tampubolon, Syahron Lubis \\ Universitas Sumatera Utara (USU), Medan, Indonesia \\ E-mail: ruthtampubolon7@gmail.com
}

Received: 2021-11-07

Accepted: 2021-12-2

\begin{abstract}
The study aims to describe the speech errors and find out the causes of the speech errors in the video podcast Get Real Giving thanks with Sam Kim Ep 22. The researchers collected data using the documentation method and applied qualitative analysis. The data for this research were the utterances from the video podcast Get Real Giving thanks with Sam Kim Ep 22. The data source was a video between the hosts, Ashley and BM, and the guest, Sam Kim, which was downloaded from the official DIVE Studios YouTube Channel with durations of 46 minutes. The data were described based on the theory of Common Speech Errors by Clark \& Clark (1977). According to the results, it was shown that Ashley made nine types of errors totaling 47 errors, but BM made eight types, so he did not make errors in types of stutters totaling 80 errors, and Sam made nine types totaling 106 errors. The causes of the speech errors are due to internal and external factors such as nervousness, hesitation, haste, and lacking concentration. The total number of speech errors made by the speakers is 233 mistakes. The speech errors happened as many as 52 repetitions, and Sam did it the most. In filled pause, 46 mistakes occurred, and Sam as well as BM produced the most errors. In silent pause, 41 errors occurred 41, and all speakers made the errors. In interjections, 37 mistakes occurred, and Ashley made the fewest mistakes. In false starts (unretraced), 14 mistakes occurred, and BM as well as Ashley made 4 mistakes. In corrections, 13 mistakes occurred, and BM only made two mistakes. In stutters, 13 mistakes happened, and Asley and Sam made the most mistakes, but BM did not make any mistake. In a slip of the tongue, 11 mistakes occurred, and Ashley made only one mistake. In false starts (retraced), which is the least common type, 6 mistakes occurred.
\end{abstract}

Keywords: Speech Errors, Video Podcast, Common Speech Errors, DIVE Studios YouTube Channel

\section{Introduction}

Psycholinguistics is the study of language behavior and using language to communicate ideas and the mental representations and processes involved in language use, including the production, understanding, and storage of spoken and written language. The main focus of Psycholinguistics is language acquisition, language understanding, and language production. Kempen (1987) stated that in psycholinguistics, two components become the object of study: humans and language. Psycholinguistics deals with how language is produced, felt, 
Speech Error in "Get Real Giving Thanks with Sam Kim Ep \#22 by Dive Studios" Video Podcast, Ruth Intan Angraeni Tampubolon, Syahron Lubis

understood, and remembered. Psycholinguistics discusses speech in language acquisition. In Psycholinguistics, speech production or a spoken sentence has a special function: to inform, ask, and warn about something. Speech Production, the process involved in converting ideas into spoken speech, addresses the stages of speech planning, the mental units involved, and interesting questions such as how far ahead of time one chooses words when one starts speaking. The production of language is closely related to doubt and pause. These doubts and pauses are usually referred to as a part of Speech Error (Clark \& Clark, 1977).

In Speech Errors, many utterances are characterized by hesitations, repetitions, false start, and filler such as um, well, or you know. According to Deese (1978) speakers use complete sentences, $98 \%$ of which were grammatically correct. Speech Errors occur regularly in everyday conversation.

Podcasts are episodes of programs available on the Internet. Podcasts are usually the original audio or video recordings, but they can also be recordings of a television broadcast or radio program, lecture, show, or other programs (Brown \& Green, 2007). Berry (2006) defined a podcast as a converged application that can create, collect, and distribute personal audio and video programs freely through new media and collect various formats such as $\mathrm{mp} 3$, pdf, and ePub. The researchers resolved to study the Speech Error on Video Podcast Get Real by DIVE Studios in this research. DIVE Studios is a podcast networking company that was founded in July 2019. DIVE Studios has a variety of podcasts with interesting and very up-to-date topics; pop culture, young adulthood, music, K-Pop, movie reviews, random things, and all the issues very close to young people. In this research, the researchers specifically studied the Speech Errors on Video Podcast Get Real Giving Thanks with Sam Kim Ep \#22. BM, Ashley, and Peniel hosted the show on Thursday, November 28th, 2020.

Based on the introduction of the study, the research problems were formulated as follow:

1. What speech errors occurred on the Video Podcast Get Real Giving thanks with Sam Kim Ep \#22?

2. What were the causes of the speech errors?

Based on the problems of the study stated earlier, this research has the following objectives:

1. To describe the types of speech errors in the Video Podcast Get Real Giving thanks with Sam Kim Ep \#22.

2. To find out the causes of the Speech Errors.

This research focuses on the causes, and the types of Speech Errors that occur in the Video Podcast Get Real Giving Thanks with Sam Kim Ep \#22, both the host and the guest in the podcasts. In this research, the researchers used the theory of Clark and Clark (1977) and applied qualitative method research to describe the types of speech errors and find out the causes of the speech errors.

\section{Literature Review}

Several previous studies on Speech Errors have been carried out by previous researchers. Awad and Fathy (2020) conducted a study entitled "Spontaneity of Speech Errors: A Diagnostic Psycholinguistic Case Study". Awad and Fathy in their research focused on the use of speech errors as a verbal communication tool to clarify the psychological aspects of George W. Bush's characters. To achieve their research objectives, they adopted 
a psycholinguistic approach in addition to the set of sound production models proposed by Dell (1999), and Chang and Griffin (1999). The main results of the study were, (A) Phonological errors and morphologically, (b) Freudian Bush slip - caused by psychophysiological factors, such as fatigue, excitement, and distraction (c) Bush syntactic errors, caused by improper lexical insertion, (d) Economic use of speech disfluencies, which caused by a problem in the recognition system.

In addition, Nooteboom and Quené (2019) also conducted a study on Speech Errors where in their research entitled "Correcting speech errors: Competition as a Source of Improvement," they focused their research on sources of self-repairs of segmental speech errors during self-monitoring. The potential sources of repairs were candidate forms competing with the form under production. Their journal used the theory of repairing that derived four main predictions specific for classical SLIP experiments: (a) Error-to-cutoff mistakes were shorter after single elicited errors than after other errors. (b) Single elicited errors were relatively more often detected than other errors, but more so after internal than external error detection. (c) The correct form is the most frequently used as repair, but more so for single elicited than other errors. (D) Cutoff-to-repair mistakes were shorter for single elicited than for other errors.

The focuses on these two studies are different from the research the authors carried out in which the authors focused the research on the causes, and the types of Speech Errors that occur in the Video Podcast Get Real Giving Thanks with Sam Kim Ep \#22, both the host and the guest in the podcasts.

Gleason and Ratner (1998) define speech disfluencies as a speech by speakers with the characteristics of doubt, repetition, initial errors, and fillers, e.g., as um, well, eh, etc. There are common types of errors according to Clark and Clark (1977: 263) as follows:

\section{a. Silent pause}

A silent pause means a silent period between any words. A period of silence between words can be called a brief pause. A silent pause occurs when the speaker pauses a second or more of a word. Silent pause is symbolized by [//].

\section{b. Filled pause}

The Filled pause means that the gap is filled with speech sounds such as um, ehh, uh, em, aa, etc. Like "I think [em] she's really pretty" "She's like [ehh] wise but [aa] really loud". This filled pause, resulting in a full pause because they think if they waited too long to plan their following speech. Filled pause is symbolized by $[, \ldots . . . .$,

\section{c. Repeat}

A repeat occurs when the speaker repeats one or more words when the person speaks very quickly and spontaneously. Repeats occur when the speaker repeats one or more spoken words. Repeats are symbolized by [/].

\section{d. False starts (unretraced)}

False starts (unretraced) correction of a word, including one or more repetitions before the correct word. In False starts (unretraced) errors, the speaker would try to pronounce the words issued correctly, but the speaker unconsciously produces the wrong words so that the speaker needs to correct the words issued. False starts (unretraced) symbolized by [ $]$. 
Speech Error in "Get Real Giving Thanks with Sam Kim Ep \#22 by Dive Studios" Video Podcast, Ruth Intan Angraeni Tampubolon, Syahron Lubis

\section{e. False starts (retraced)}

In the case of False starts (retraced) errors, the correction of a word also includes repetition of one or more words before the corrected word. When the speakers realized that they had made a speech error, they corrected their words. They make a repetition of one or more words before the corrected word. False starts (retraced) symbolized by [\\].

\section{f. Corrections}

Corrections occur when the speaker replaces certain old words with new ones, indicating that the old words were misplaced. The correction category was like wrong starters, except that they contain an explicit correction phrase as I meant-or rather, well, or that marks the phrase as a correction. Corrections symbolized by [-].

\section{g. Interjections}

Interjections indicate that the speaker should pause to think about what to say next. An interjection is indicated, a pause of hesitation, indicating that the speaker should stop thinking about what to say next. The interjection words were like oh, ah, well, and say. English words used mostly as interjections include ugh, wow, ouch, etc. Interjections symbolized by $\left[* . . .{ }^{*}\right]$

\section{h. Stutters}

Stutters occur when a speaker is in doubt, tripped, tense, jerks, or nervous. Stuttering is signed by repeating one letter or syllable several mistakes before a particular word is spoken next. Stutters is symbolized by [- - - ].

\section{i. Slips of the tongue}

Slips of the tongue occur when the speaker's actual speech differs from the intended speech. It involves involuntary movement, addition, deletion, mixing, or substituting material in a speech and can be phonological, morphological, lexical, or syntactic. A slip of the tongue is symbolized by $[\rightarrow]$.

\section{Research Method}

This research was conducted using a qualitative research method. The data of this research were in the form of utterances through the transcript described descriptively based on the transcript. According to Moleong (1995), descriptive qualitative is a type of research that results from descriptive data in written or oral words from an observed object or the data source. Besides, the data would be interpreted and displayed descriptively and systematically based on supporting theories. The method of data analysis for the research was content analysis. It was focused on the characteristics of language as communication by paying attention to the content or contextual meaning of the text (Tesch, 1990). The primary data of this research was the utterances spoken by the host and guest Get Real Giving Thanks with Sam Kim Ep \#22. The source of data in this research was a video podcast on Youtube (https://www.youtube.com/watch?v=Nq3LOwHBza8\&t=206s).

The researchers performed several procedures to obtain the data described in this research. The data were described following the theory proposed by Miles, Huberman, and Saldana (2014) in which the technique was focused on four characteristics; data collection, data condensation, data display, and conclusions (drawing/verification). Since this research 
used a qualitative descriptive method, the data described were carried out in words, not in numbers or statistical procedures.

\section{Results and Discussion}

\subsection{Types of Speech Errors}

\section{Silent Pause $[/ /]$}

\section{DATA I}

BM : We're hungry //, but for many uh // but a lot other Korean-Americans working abroad, we didn't have a chance to spend the holiday at home with our family and friends.

The mistake made by BM, who made two silent pause mistakes at the same time in one sentence, which was hungry//but for a lot of uh//but.

\section{DATA II}

BM : So, it's not really Thanksgiving, guys, but // when you hear that, it's Thanksgiving Day. Those errors were in the example, but//when you hear that he chose to stop thinking the word he would say next.

\section{DATA III}

Sam : Definitely it's it's definitely like it's it's different when you come into your house //, and there's like nothing.

Sam made, your house // and there's, from the first word he said, he felt it wasn't right.

\section{DATA IV}

Ashley : Just like their // likeability.

In this case, Ashley was irritated by the silent pause as she was unsure what words to say, so he continued speaking after a 2-5 second pause with the word their // likeability.

\section{DATA V}

BM : Thankful for // life. I'm thankful for // Negativity. I'm thankful for // eh nature. thankful for // headphones. Thankful for // good coffee.

BM hesitated a lot to continue his words, and there was a lot of silence $2-6$ seconds in the sentence for // life, for // Negativity, for // eh nature, for // headphones, and for // good coffee.

\section{Filled Pause $[, \ldots . . .$,}

\section{DATA I}

Sam : Yesss, I'm Sam Kim. I, hmm, I love music.

Sam did Filled pause in his sentence I, hmm, I love music.

\section{DATA II}

Ashley : I just feel comfortable when I'm at home, you know, just like, no stress.

Ashley shows you know as a form of wanting others to understand what he said without explaining it.

\section{DATA III}

Sam : When you come into your house umm and there's like nothing. A year or so ehh I had to put him in the hospital. 
Speech Error in "Get Real Giving Thanks with Sam Kim Ep \#22 by Dive Studios" Video Podcast, Ruth Intan Angraeni Tampubolon, Syahron Lubis

Sam needed some time and thought to consider what words to say, so he did a full pause umm, uhh.

\section{DATA IV}

Ashley : And you know after thanksgiving.

Ashley used a filled pause you know, and it shows that Ashley produced a full pause for waiting and thinking.

\section{DATA V}

BM : Ohh you know what, I remember hitting the mall.

BM made mistakes by filling it in clearly with the sentences you know.

\section{Repeats $[/]$}

\section{DATA I}

Sam : Hello / hello.

Hello / hello in this sentence Sam could say the word Hello only once, but he chose to repeat the word.

\section{DATA II}

BM : It's a good day / It's a good day.

In this case, it was shown that BM always repeats the words many mistakes without realizing it, resulting in speech error repeats.

\section{DATA III}

Sam : It's / It's a it's a newer game. It / it got the point. Because I was / I was tired.

It's / it's a newer game. It / it got the point. Because I was / I was tired of one sentence that he said had been repeated a lot without realizing it was always doing it.

\section{DATA IV}

Ashley : When I first came to Korea like / like ehm.

Ashley repeated in the sentence like / like um, Ashley should have said this sentence once but unconsciously she chose to repeat it without realizing it.

\section{False Starts (Unretraced) [ $\mathrm{U}$}

\section{DATA I}

Ashley : Seollal umm Chinese thing \like Lunar years.

Ashley corrected a word she said before and entered a new and correct word, namely Chinese thing \like Lunaryears from the word Chinese and changed to lunar years.

\section{DATA II}

BM : Alright let's talk \that's enough about games.

BM itself, which was in the sentence Alright let's talk \That's enough about the game.

\section{DATA III}

BM : I'll the ref $\backslash$ I'll be the judge.

BM in the sentence I'll the ref $\backslash$ I'll be the judge, initially, BM said that he would be a ref, but the end, he replaced the word with judge. 


\section{DATA IV}

Sam : I haven't \I have never done this before.

From the data IX above, Sam made only one unretraced error. Namely, I haven't \I have never done this before in the sentence.

\section{False Starts (Retraced) [II]}

\section{DATA I}

Sam : How the age gap II what is the age gap between you and your brothers?

Sam made one mistake in the sentence How the age gap II what is the age gap between you and your brothers.

\section{DATA II}

BM : So, she's it's been third thing just \It's been her the third Thanksgiving.

BM made a retraced error in the sentence it's been third thing just \It's been her the third Thanksgiving, that was, he corrects the initial sentence and repeated it until finally fixing it with a new sentence.

\section{Correction [-] \\ DATA I}

Ashley : I know for us -well for Korean Americans.

Ashley made errors in the sentence I know for us -well for Korean Americans, in this case, Ashley included the word-well.

\section{DATA II}

Sam : My specialty -well I love cooking.

Sam made errors in the sentences -well.

\section{Interjection $\left[{ }^{*} \ldots . . . *\right]$}

\section{DATA I}

Sam : *Ohh*, yes.

Sam wanted to continue his next words by saying *Ohh*, which was also indicated by pausing and thinking about what words he would say next.

\section{DATA II}

Sam : *Ohh* the PS5 is coming out soon.

By filling in the interjection with the word *Ohh*, and it was also shown hesitantly and requires a pause to think so that the interjection of the sentence occurred.

\section{DATA III}

BM : *Ohh* you're a cat guy.

Errors interjections only the filler *Ohh* comes out by BM. And this proves that he was also hesitant to continue the next word.

\section{DATA IV}

Sam : *Ohh* my god jc penny right.

Filled in the interjections with the word *Ohh*, and this also shows pauses and hesitates to continue with new words. 
Speech Error in "Get Real Giving Thanks with Sam Kim Ep \#22 by Dive Studios" Video Podcast, Ruth Intan Angraeni Tampubolon, Syahron Lubis

\section{Stutters [- - - ]}

\section{DATA I}

Sam : Yesss, I-I-lam Sam Kim.

In the word I-I-I am; in this case, Sam could immediately say I am, but due to excessive nervousness.

\section{DATA II}

Ashley : Dude. It-it-it's tastes like a lime.

Ashley was so hesitant to continue her word that she stutters about it, It-it's-it's.

\section{DATA III}

Ashley : Than-than-thanksgiving they have macy's parade.

In this case, Ashley stutters in the words Than-than-thanksgiving.

\section{DATA IV}

Sam : That's what I do actually I-I-I just throw on a steam.

He repeated the word countless mistakes in I-I-I words.

\section{Slips of the tongue $[\rightarrow]$}

\section{DATA I}

BM : Like testy now $\rightarrow$ Like testing now.

Like testy now, it should refer to the sentence Like testing now, which means that when BM speaks one of the two words skips one part of the word from testy $\rightarrow$ testing.

\section{DATA II}

BM : That kinda stuff $\rightarrow$ That kind of stuff.

From the data II above, BM made an error slip of the tongue blends. He combineds two words into one, namely in the word kinda $\rightarrow$ kind of.

\section{DATA III}

BM : Jazzy Penney $\rightarrow$ JC Penney.

In the sentence, he said it was Jazzypenney when in fact it was the word JCpenney where Jazzy $\rightarrow$ JC.

\section{DATA IV}

BM : I'mma treat her $\rightarrow$ I'm going treat her.

In the sentence I'mma treat her $\rightarrow$ I'm going treat her. Where he blends two words into one word, namely I'mma $\rightarrow$ I'm going.

\subsection{Causes of Speech Errors}

Speech errors could be caused by a variety of factors. The cause of speech errors was that speakers spoke spontaneously rather than waiting and thinking for long periods of time to get the words out. Speech errors can be affected by a multitude of factors, including internal and external causes, as well as situational anxiety and social factors. Some of the causes of speech errors during the video podcast are listed below. 


\section{Nervousness}

Nervousness was the main factor causing speech errors in this podcast video. Nervousness was the most visible factor during the host and Sam's video podcasts as the guest.

\section{Hesitating}

Hesitating was also a factor in speech errors in the podcast video. In this regard, a lot of hesitation occurred throughout the video podcast.

\section{Haste}

Haste was also a factor in speech errors in the video podcast. Haste was one of the attitudes where when someone speaks, it would cause speaking errors because they were too hasty to issue new words.

\section{Lacking concentration}

Lacking concentration was also a factor in speech errors in the video podcast. Lacking concentration when someone talking, then someone messes up the concentration, such as the interlocutor or the distraction around him.

\subsection{Discussion}

Based on the analysis of the data in the Video Podcast, it was vividly revealed that all the nine types of speech errors based on the theory proposed by Clark and Clark (1977) had been done by the hosts of Get Real, Ashley and BM, and also by the guest, Sam Kim.

After describing the data from the existing text transcripts, the researchers revealed that all kinds of speech errors existed from silent pause, filled pause, repeats, false starts (unretraced), false starts (retraced), corrections, interjections, stutters, and slip of the tongue were found in the video podcast. From the entire video podcast, the speakers made various speech errors. Ashley made 47 speech errors, BM made 80 speech errors, and Sam made 106 mistakes. From this data it is clear that Sam has made the most mistakes compared to Ashley and BM.

The total number of speech errors made by the speakers was 233 mistakes. Based on the results, it was found that the speakers in the video podcast produced the most mistakes in repeats; that is with the number of 52 mistakes, followed by pauses 46 mistakes, silent pause 41 mistakes, interjections 37 mistakes, false starts (unretraced) 14 mistakes, corrections, stutters 13 mistakes, slip of the tongue 11 mistakes, and false starts (retraced) 6 mistakes. The first cause was nervousness. It was the main factor causing speech errors in this podcast video. The second cause was hesitating, the third cause was haste, and the last cause was lacking concentration. This happened because the speakers did not focus while they were talking so that their concentration was easily distracted by the circumstances around them.

\begin{tabular}{|c|c|c|c|c|}
\hline \multirow{2}{*}{ Types Of Speech Errors } & \multicolumn{3}{|c|}{ SPEAKERS } & \multirow{2}{*}{ TOTAL } \\
\cline { 2 - 4 } & Ashley & BM & Sam & 41 \\
\hline Silent Pause & 5 & 14 & 22 & 46 \\
\hline Filled Pause & 12 & 17 & 17 & 52 \\
\hline Repeats & 9 & 16 & 27 & 14 \\
\hline False Starts (Unretraced) & 4 & 4 & 6 & 6 \\
\hline False Starts (Retraced) & 1 & 3 & 2 & \\
\hline
\end{tabular}


Speech Error in "Get Real Giving Thanks with Sam Kim Ep \#22 by Dive Studios" Video Podcast, Ruth Intan Angraeni Tampubolon, Syahron Lubis

\begin{tabular}{|c|c|c|c|c|}
\hline Correction & 5 & 2 & 6 & 13 \\
\hline Interjections & 7 & 17 & 13 & 37 \\
\hline Stutters & 3 & - & 10 & 13 \\
\hline Slips Of the Tongue & 1 & 7 & 3 & 11 \\
\hline Total & 47 & 80 & 106 & 233 \\
\hline
\end{tabular}

\section{Conclusion}

Speech errors are very common, and often occur when the speakers are talking, whether in childhood or adults. Speech errors also occur on the Video Podcast Get Real Giving Thanks with Sam Kim Ep \# 22. In the video, the hosts were Ashley and BM, and the guest Sam Kim. All of them made speech errors during the video podcast. Based on the theory of Clark and Clark (1977), the researchers discovered that there were nine types of speech errors that were carried out by the hosts and guest, except for BM, who did not make any mistakes in stutters during the video podcast. A total of 233 speech errors occurred during the 46 minutes of the video podcast. The frequency of speech errors made by the hosts and the guests during the video podcast varied. Speech errors made by three speakers, Ashley, BM, and Sam were caused by internal and external factors, such as anxiety and the social environment. The source of the speech error was taken from speech errors generated by the hosts and guest. The speakers in the video podcast had almost the same errors. Besides, the causes of their speech errors were almost the same too. The three speakers on the video podcast were nervous when they were about to say their words. This is the main cause of them making speech errors because if someone is already feeling nervous then what is stored in the brain can suddenly be lost. Hesitation is also a factor in the speech errors found in video podcasts. Throughout the video podcast, many doubts arise in this regard. Haste is also a contributing factor when speakers make speech errors on video podcasts. The last thing that causes them to make speech errors is a lack of concentration. Lack of concentration is also a factor in speech errors in the video podcasts. It can happen when one person interferes with concentration or the situation around them while the other is talking. For the implications of the findings and suggestions for future research, it is hoped that students who are interested in linguistic studies can learn and understand more deeply about speech errors. Every researcher who is interested in conducting related research is expected to learn the importance of understanding speech errors and how to solve them so that they can avoid making speech errors or minimize them.

\section{References}

Awad, M., \& Fathy, N. (2020). Spontaneity of Speech Errors: A Diagnostic Psycholinguistic Case. International Journal of English Linguistics, $X$, 92-107.

Berry, R. (2006). Would the IPod Kill the Radio Star? Profiling Podcasting as Radio. Convergence Journal, 12(2), 143-162.

Brown, A., \& Green, T. D. (2007). Video Podcasting in Perspective: The History, Technology, Aesthetics, and Instructional Uses of a New Medium. Journal of educational technology systems, 36(1), 3-17.

Clark, H. H., \& Clark, E. V. (1977). Psychology and Language. New York: Harcourt Brace Jovanovich.

Deese, J. (1978). Thought into speech. American Scientist, 66, 314-321.

Kempen, G., \& Hoenkamp, E. (1987). An incremental procedural grammar for sentence formulation. Cognitive Science 11: 201-258. 
Gleason, J.B., \& Ratner, N.B. (1998). Psycholinguistics Second Edition. United States of America: Thomson wadsworth.

Miles, M. B., Huberman, M. A., \& Saldana, J. (2014). Qualitative Data Describe. London: Sage Publication.

Moleong, L.J. (1995). Metode penelitian. Bandung: Remaja Rosda Karya.

Nooteboom, S \& Quené, H. (2019). Repairing speech errors: Competition as a source of repairs. Journal of Memory and Language: 114.https://doi.org/10.1016/j.jml.2019.104069.

Tesch, R. (1990). Qualitative research: Analysis types and software tools. Bristol, PA: Falmer. 